\title{
3 Research S Suare \\ Screening of Major Bioactive Compounds Profile of Pomegranate Peel Waste by Using HPLC
}

\section{Nishant Kumar}

National Institute of Food Technology Entrepreneurship \& Management

\section{Pratibha}

National Institute of Food Technology Entrepreneurship \& Management

\section{Neeraj}

National Institute of Food Technology Entrepreneurship \& Management

Rokayya Sami ( $\sim$ rokayya.d@tu.edu.sa )

Taif University

\section{Ebtihal Khojah}

Taif University

\section{Sultan J. Alsufyani}

Taif University

\section{Amina A. M. Al-Mushhin}

Prince Sattam Bin Abdulaziz University

\section{Research Article}

Keywords: Pomegranate peel waste, Freeze drying, Methanol, Bioactive compounds, HPLC

Posted Date: November 30th, 2021

DOI: https://doi.org/10.21203/rs.3.rs-1068729/v1

License: (c) (i) This work is licensed under a Creative Commons Attribution 4.0 International License.

Read Full License 


\section{Abstract}

Bioactive compound characterization is an important steps for utilization of pomegranate peel waste as food and nutraceutical ingredients. In the present investigation the effects of different drying (freeze, trayoven and sun) and solvents such as methanol, ethanol, water, acetone and hexane were investigated on the extraction and recovery of major bioactive compounds (ellagic acid, gallic acid, quercetin and punicalagin) of pomegranate peel for two pomegranate varieties (i.e. Bhagwa and Ganesh) using high performance liquid chromatography (HPLC). The results indicated that the peel powder obtained by freeze drying $\left(-45^{\circ} \mathrm{C}\right)$ method which extracted by methanol was higher amount in bioactive compounds compared to the other drying methods and solvents. Freeze dried peel powder of Bhagwa pomegranate showed higher amount of gallic acid $(32.2 \mathrm{mg} / \mathrm{g})$, ellagic acid $(13.6 \mathrm{mg} / \mathrm{g})$, punicalagin $(15.2 \mathrm{mg} / \mathrm{g})$ and quercetin $(2.5 \mathrm{mg} / \mathrm{g})$ with methanol solvent as compared to the other extract of Bhagwa and Ganesh varieties. Basis on the results of current study it can be concluded that the freeze drying method for drying pomegranate peel powder and methanol as a solvent are effectives to recover higher extraction of bioactive compounds which can be utilize to develop human and animal health.

\section{Introduction}

Pomegranate fruit is known as Super fruits due to its delicious taste. It contains approximately $48-50 \%$ as waste of total fruits after juice extraction, which corresponds the pomegranate peel waste ${ }^{1-2}$. The pomegranate peel is important source for natural bioactive compounds such as ellagitannins, tannis, gallic acid, punicalagin, catechin, rutinpunicalin, laempferol, luteolin, glycosides and epicatechin among other phenolic compounds ${ }^{3-7}$. Despite that the gallic acid, ellagic acid, punicalagin and quercetin are considered major bioactive compounds of pomegranate peel. These bioactive compounds are responsible for the different biological activities such as antimicrobial, antioxidant, anticancer, antimutagenic, and anti-inflammatory and help to reducing the risk of chronic and cardiovascular diseases ${ }^{8-}$ ${ }^{10}$.Several researchers have reported the biological activities and functions of pomegranate peel ${ }^{11-12}$. However, the drying methods are very important factors for the drying of products to removing water and reducing the chemical reaction or enzymatic activities ${ }^{13-17}$.The drying methods can affects the quality attributes such as color, nutritional and phytochemical activities of products ${ }^{10,18-20}$. Various types of drying methods such as sun drying, vacuum drying, freezing drying, oven drying and air drying etc. are used to drying the products ${ }^{21}$. Furthermore the freeze drying known as potential method for extraction and higher recovery of bioactive compounds and other phytochemical from natural plant sources compared to other drying methods; however the freeze drying method is expensive method compared to other but retained higher quality of the products ${ }^{22-25}$.

In addition, the extraction of bioactive compounds from plant sources is considered as primary steps and the solvents are important factors for the extraction and recovery of bioactive compounds. Several types of solvents i.e. polar and non-polar are used to extract the bioactive and phenolic compounds from plant. Generally, the non-polar and low polar solvents are used to extract lipophilic compounds and pigments 
from plant. However, the recovery of phenolic compounds, yield and their free radical scavenging activity, antimicrobial and other biological activities of pomegranate peels and other plants are depending on the types of solvents and extraction procedure ${ }^{12,26-30}$. Numerous studies Mphahlele et al., 9 ; John et al., 31 ;

Ngo et al., ${ }^{32}$; Buitrago et al., ${ }^{33}$ have reported that the drying and solvent has an impact on the extraction and recovery of the bioactive compounds from pomegranate peel. Moreover, the effects of drying methods and solvents on the extraction \& recovery of bioactive compounds and HPLC quantification of bioactive compounds from pomegranate peel have very limited studied.

\section{Materials And Method}

Study period. All the experiments were conducted during January 2018 to December 2018 at National Institute of Food Technology Entrepreneurship ad Management (India) and Sophisticated Industrial Materials Analytic (SIMA)Lab Pvt. Ltd. Delhi India.

\section{Materials}

The fresh pomegranate fruits were procured from pomegranate orchard, Kullu, Himachal through National Research Center on Pomegranate (NRCP- ICAR), Solapur, Maharashtra (India). The study complies with local and national guidelines.

Chemical and reagents. The analytical grades of chemicals, reagents and standards purchased from Sigma Aldrich Inc. and Hi-Media, India.

Preparation of peel powder. The pomegranates were peeled manually to obtain the peel. The peel as obtained was subjected to different drying methods to obtain peel powders (PGP). The blanching of obtained fresh pomegranate peel was carried out in water bath at $90^{\circ} \mathrm{C}$ for $30 \mathrm{sec}$ to remove surface impurities and contamination and dried under three different conditions viz., freeze drying $\left(-45^{\circ} \mathrm{C}\right.$ for 32 h), tray-oven $\left(60^{\circ} \mathrm{C}\right.$ for $\left.29 \mathrm{~h}\right)$ and sun dried $(72 \mathrm{~h})$ respectively (Figure 6).

Ultrasonic Extraction. The dried peel powder obtained from the peels of Bhagwa and Ganesh was used for the extraction of phenolic and flavonoid content using polar (viz., methanol, ethanol, water, acetone) and non-polar solvents (hexane) through ultra-sonic assisted extraction method. The fine powder samples $(0.2 \mathrm{~g})$ of pomegranate peel of both varieties were sonicated in $10 \mathrm{ml}$ of different solvents using an ultrasonic bath (CUB-5, Citizen, $40 \mathrm{kHz}, 220-240 \mathrm{~V}$, India) for $30 \mathrm{~min}$ at $45^{\circ} \mathrm{C}$ temperature ${ }^{10}$. The prepared solution was centrifuged (Sigma, 3-18, KS, Germany) at $5^{\circ} \mathrm{C}$ for 10 min with 8654 RPM and filtered using Whatman No. 11 filter paper to obtain the transparent extract. In total, there were three pomegranate peel powder samples for each variety prepared through three different drying methods (freeze drying, tray drying, and sun drying). For each type of powder, five solvents (methanol, ethanol, water, acetone, and hexane) were used for preparing extracts. The peel extracts were later used for estimation of total phenolic content, total flavonoid content, antioxidant and antibacterial activity. The quantification of major phenolic content in the pomegranate peel of both the varieties was also done by HPLC analysis. The 15 type's extract of pomegranate peel powder for each variety was constructed with 
the completely randomized design (CRD) of research. The coding of extracts as prepared has been presented in Table 2.

Table 2.Prepared extraction of different dried pomegranate peel powder ( $\mathrm{Cv}$. Bhagwa\& Ganesh) with different solvents

S.No. Pomegranate peel (varieties) powder

\begin{tabular}{|c|c|c|c|c|c|c|}
\hline & \multicolumn{3}{|c|}{ Bhagwa pomegranate } & \multicolumn{3}{|c|}{ Ganesh pomegranate } \\
\hline & Drying & Solvents & Coding* & Drying & Solvents & Coding* \\
\hline 1 & Freeze & Methanol & BFDM & Freeze & Methanol & GFDM \\
\hline 2 & Freeze & Ethanol & BFDE & Freeze & Ethanol & BGFDE \\
\hline 3 & Freeze & Water & BFDW & Freeze & Water & GFDW \\
\hline 4 & Freeze & Acetone & BFDA & Freeze & Acetone & GFDA \\
\hline 5 & Freeze & Hexane & $\mathrm{BFDH}$ & Freeze & Hexane & GFDH \\
\hline 6 & Tray & Methanol & BTDM & Tray & Methanol & GTDM \\
\hline 7 & Tray & Ethanol & BTDE & Tray & Ethanol & GTDE \\
\hline 8 & Tray & Water & BTDW & Tray & Water & GTDW \\
\hline 9 & Tray & Acetone & BTDA & Tray & Acetone & GTDA \\
\hline 10 & Tray & Hexane & BTDH & Tray & Hexane & GTDH \\
\hline 11 & Sun & Methanol & BSDM & Sun & Methanol & GSDM \\
\hline 12 & Sun & Ethanol & BSDE & Sun & Ethanol & GSDE \\
\hline 13 & Sun & Water & BSDW & Sun & Water & GSDW \\
\hline 14 & Sun & Acetone & BSDA & Sun & Acetone & GSDA \\
\hline 15 & Sun & Hexane & BSDH & Sun & Hexane & GSDH \\
\hline
\end{tabular}

Where; $\mathrm{BFD}=$ Bhagwa freeze dried, $\mathrm{BTD}=$ Bhagwa tray dried, $\mathrm{BSD}=$ Bhagwa sun-dried, $\mathrm{GFD}=$ Ganesh freeze dried, GTD= Ganesh tray dried, $G S D=$ Ganesh sun-dried, $(M=$ methanol, $E=$ ethanol, $W=$ water, $A=$ acetone, $H=$ hexane $)$,

HPLC analysis of samples. The identification and quantification of the major bioactive compounds i.e. gallic acid, ellagic acid, punicalagin and quercetin etc. from pomegranate peel extract were determined using analytical reverse phase HPLC_4D UV (Agilent, 1200, HPLC Infinity) method followed by Elango et al., ${ }^{34}$ and Venkataramanamma et al., ${ }^{35}$ with minor modifications. HPLC column (C-18, Length- $250 \times 4.6$ $\mathrm{mm}$ id) with pore size of $5 \mu \mathrm{m}$ was used for investigation at $260 \mathrm{~nm}$ UV wavelength by UV-PDA detector. The column speed for auxiliary draw and eject was set at 200 and $400 \mu \mathrm{L} / \mathrm{min}$ respectively with constant flow rate (0.8). Solvent A $(0.12 \mathrm{w} / \mathrm{v})$ potassium dehydrate phosphate buffer with water at $\mathrm{pH} 1.2$ and 
Solvent B acetonitrile were used to investigation. The details about the gradient program for solvents (A \& B) of HPLC summed up in Table 3

Table 3.Gradient Programmode for isolation of the bioactive compounds of pomegranate peel extract

\begin{tabular}{|lll|}
\hline Time (min) & Solvent (A) \% & Solvent (B) \% \\
\hline 0 & 95 & 5 \\
\hline 15 & 45 & 55 \\
\hline 20 & 30 & 70 \\
\hline 25 & 95 & 5 \\
\hline
\end{tabular}

Identification and Quantification of compounds. HPLC chromatogram was used to identification and quantification of bioactive compounds in pomegranate peel extract by retention time (Rt), area and height respectively. The results of bioactive compounds of each samples are expressed as $\mathrm{mg} / \mathrm{g}$ of extract

Statistical analysis. Completely randomized design (CRD) was used to perform experimental work. Average value with standard deviation (SD) was expressed as results. Data were statistically analyzed using ANOVA and Post Hoc triplicate range test at $\mathrm{P}<0.05$ significance level by IBM SPSS software (24.0). Origin Pro (2019b) was used to graphically representation of average data.

\section{Results}

HPLC chromatogram of standards. The chromatograms of phenolic compounds standards such as ellagic acid, gallic acid, quercetin, and punicalagin in terms of retention time, area and height are shown in Table 1 and Figure 1. The maximum area was found of gallic acid with 7.25 min retention time, followed by ellagic acid with $42.05 \%$ area and $53.38 \%$ height with 4.077 retention time. In the standard chromatogram, punicalagin showed minimum area $(0.32 \%)$, height $(0.47 \%)$ with a 14.77 min retention time. The maximum retention time was taken by a punicalagin standard with the lowest area and height. The maximum height was recorded by the ellagic acid standard as compared to others. The results of chromatograms of the standards are supported by the previous studies done by John et al., 31; Qu et al., 36; Farag et al., ${ }^{37}$; Singh et al., ${ }^{38}$. 
Table 1

HPLC chromatograms of phenolic standards (ellagic acid, gallic acid, quercetin, and punicalagin)

\begin{tabular}{|llll|}
\hline Compounds & Retention Time (min.) & Area (\%) & Height (\%) \\
\hline Ellagic acid $\left(\mathrm{C}_{14} \mathrm{H}_{6} \mathrm{O}_{8}\right)$ & 4.07 & 42.05 & 53.38 \\
\hline Gallic acid $\left(\mathrm{C}_{7} \mathrm{H}_{6} \mathrm{O}_{5}\right)$ & 7.25 & 50.57 & 38.69 \\
\hline Quercetin $\left(\mathrm{C}_{15} \mathrm{H}_{10} \mathrm{O}_{7}\right)$ & 14.36 & 7.05 & 7.45 \\
\hline Punicalagin $\left(\mathrm{C}_{34} \mathrm{H}_{22} \mathrm{O}_{2}\right)$ & 14.77 & 0.32 & 0.47 \\
\hline
\end{tabular}

Ellagic acid. The results pertaining to extraction of ellagic acid from three different types of pomegranate peel powders extract have been presented in Figure 2. The ellagic acid compound was estimated through $\mathrm{HPLC}$ and has been expressed as $\mathrm{mg} / \mathrm{g}$ of peel powder. The results indicated that there was a significant impact of specific solvent used to extract the ellagic acid in both Bhagwa and Ganesh peel powders. Apart from solvents used, there was also a significant impact of the method of drying to prepare the peel powders on ellagic acid content. Among various solvents used, extracts prepared with methanol solvent showed the highest ellagic acid content in all the three types of peel powders (freeze dried, tray dried, and sun dried) followed by ethanol, water (control) and acetone in both the pomegranate varieties. The least ellagic acid content was recovered with hexane being used as an extraction solvent. The ellagic acid content recovered using different solvents were also statistically significant with respect to each other for a specific type of drying treatment. In peel powder of Bhagwa, the statistically significant and maximum ellagic acid content $(32.20 \pm 0.01 \mathrm{mg} / \mathrm{g})$ was recorded in freeze dried peel powder. This ellagic acid content was also statistically significant and highest as compared to all other solvents and drying treatments.

The second best result was obtained with ethanol solvent in freeze dried powder $(30.19 \pm 0.01 \mathrm{mg} / \mathrm{g})$ followed by methanol solvent in tray dried powder $(28.40 \pm 0.02 \mathrm{mg} / \mathrm{g})$. Among various drying treatments, the statistically significant and highest ellagic acid content was recovered in freeze dried powder followed by tray dried and sun dried peel powders. The least ellagic acid content was recovered in sun dried peel powder. The ellagic acid content as observed in different drying treatments was also statistically significant with respect to each other for a specific types of solvent. In peel powder of Ganesh, the statistically significant and maximum ellagic acid content $(17.50 \pm 0.02 \mathrm{mg} / \mathrm{g})$ was recorded in freeze dried peel powder. This ellagic acid content was also statistically significant and highest as compared to all other solvents and drying treatments. The second best result was obtained with ethanol solvent in freeze dried powder $(14.98 \pm 0.2 \mathrm{mg} / \mathrm{g})$. It was also observed that the ellagic acid content was statistically at par for tray dried peel powders with hexane and acetone as solvents $(1.30 \pm 0.03 \mathrm{mg} / \mathrm{g}, 1.30 \pm 0.01 \mathrm{mg} / \mathrm{g}$, respectively). It was also noted that in peel powder of Ganesh variety, irrespective of the drying treatments, the ellagic acid content was comparatively very low in acetone, hexane, and control (water) solvents as compared to methanol and ethanol. 
The obtained results showed that methanol and ethanol could be used for the extraction of ellagic acid compounds from peel powder. The freeze drying method and methanol solvent are significantly accounted to recover a higher amount of ellagic acid from pomegranate peel as compared to respective drying treatments and solvents. The hexane solvent was not detected to quantify biological compounds from pomegranate peel powder due to lower efficiency to extract high polar compounds ${ }^{17,39}$.

Gallic acid. The phenolic compound such as gallic acid passes a wide spectrum of biological activities, which include phenolic, antioxidant, and antibacterial activities, etc. ${ }^{40}$. The results pertaining to extraction of gallic acid content from three different types of pomegranate peel powders obtained from Bhagwa and Ganesh varieties have been presented in Figure 3. The results indicated that there was a significant impact of specific solvent used to extract the gallic acid bioactive compound in both Bhagwa and Ganesh peel powders. Apart from solvents used, there was also significant impact of the method of drying to prepare the peel powders on gallic acid. Among various solvents used, extracts prepared with methanol solvent showed the highest amount of gallic acid in all the three types of peel powders followed by ethanol, water, and acetone in both the pomegranate varieties. The least gallic acid content was recovered with hexane being used as an extraction solvent. The gallic acid bioactive compound recovered using different solvents were also statistically significant concerning each other for a specific type of drying treatment.

In peel powder of Bhagwa, the statistically significant and maximum gallic acid content $(16.40 \pm 0.02 \mathrm{mg} / \mathrm{g})$ was recorded in freeze dried peel powder. This gallic acid content was also statistically significant and highest as compared to all other solvents and drying treatments. The second best result was obtained with ethanol solvent $(16.20 \pm 0.10 \mathrm{mg} / \mathrm{g})$ followed by water as a extraction solvent in freeze dried powder $(13.60 \pm 0.02 \mathrm{mg} / \mathrm{g})$. Among various drying treatments, the statistically significant and highest gallic acid content was recovered in freeze dried powder followed by tray and sun dried peel powders. The least gallic acid content was recovered in sun dried peel powder. The gallic acid content as observed in different drying treatments was also statistically significant with respect to each other for a specific type of solvent. The least recovery of gallic acid from peel powder of Bhagwa pomegranate was found with hexane solvent $(5.40 \pm 0.01 \mathrm{mg} / \mathrm{g})$ in freeze dried followed by tray dried $(0.80 \pm 0.02 \mathrm{mg} / \mathrm{g})$ respectively. The peel powder obtained by sun drying treatment was not found effective for recovering gallic acid compounds with hexane solvent. In peel powder of Ganesh, the statistically significant and maximum gallic acid content $(10.90 \pm 0.03 \mathrm{mg} / \mathrm{g})$ was recorded in freeze dried peel powder. This amount of gallic acid content was also statistically significant and highest as compared to all other solvents and drying treatments. The second best result was obtained with methanol solvent in tray dried powder $(2.00 \pm 0.10 \mathrm{mg} / \mathrm{g})$. It was also noted that in peel powder of Ganesh variety, irrespective of the drying treatments, the gallic acid content was comparatively very low in ethanol, water, acetone, and hexane solvents as compared to methanol. The peel powder extraction with hexane solvent showed gallic acid compound in freeze dried $(0.80 \pm 0.02 \mathrm{mg} / \mathrm{g})$. In peel powder obtained from tray and sun drying treatments with hexane solvent not detected gallic acid compounds. In peel powder obtained from tray drying treatment also not recovers gallic acid with acetone as solvent. The results pertained that the 
maximum gallic acid was obtained with methanol as a solvent followed by ethanol in both the pomegranate varieties. The results also indicated that peel powders of Bhagwa variety recovered significantly higher amount of gallic acid as compared to Ganesh. The results demonstrated that the freeze drying method is significant potential to recovering the higher amounts of gallic acid as compared to other drying methods ${ }^{33}$.

Quercetin. The results of quantification of quercetin from pomegranate peel powders are shown in presented in Figure 4. The results indicate that there is a significant impact of specific solvent used to extract the quercetin in both Bhagwa and Ganesh peel powders. Apart from solvents used, there was also a significant impact of the method of drying to prepare the peel powders on quercetin content. Methanol as a solvent showed the highest amount of quercetin, followed by ethanol, water, and acetone solvents in both the Bhagwa and Ganesh varieties. The peel powder obtained from freeze drying was showed the statistically significant and highest amount of quercetin followed by tray and sun dried peel powder obtained from both the Bhagwa and Ganesh varieties. In peel powder of Bhagwa, the statistically significant and maximum quercetin $(2.50 \pm 0.01 \mathrm{mg} / \mathrm{g})$ was estimated in freeze dried peel powder. This quercetin was also statistically significant and highest as compared to all other solvents and drying treatments.

The second best result was obtained with ethanol solvent in freeze dried powder $(1.40 \pm 0.01 \mathrm{mg} / \mathrm{g})$ followed by water solvent in freeze dried powder $(1.10 \pm 0.10 \mathrm{mg} / \mathrm{g})$. Among various drying treatments, the statistically significant and highest quercetin content was recovered in freeze dried powder followed by tray dried and sun dried peel powders. The least quercetin content was recovered in sun dried peel powder. The quercetin content as observed in different drying treatments was also statistically significant with respect to each other for a specific type of solvent. The peel powder extraction with hexane were not quantified the quercetin compounds in all drying treatment conditions. Quercetin compound was not detected with acetone solvent in in peel powder obtained from sun drying method.

In peel powder of Ganesh, the statistically significant and maximum quercetin compound $(0.53 \pm 0.01 \mathrm{mg} / \mathrm{g})$ was recorded in freeze dried peel powder. This quercetin was also statistically significant and highest as compared to all other solvents and drying treatments. The second best result was obtained with methanol solvent in tray dried peel powder $(0.52 \pm 0.58 \mathrm{mg} / \mathrm{g})$. It was also noted that in peel powder of Ganesh variety, irrespective of the drying treatments, the quercetin compound was not detected in acetone and hexane solvents. The peel powder obtained from tray and sun drying treatments was also not showed the quercetin compounds with water solvent. Overall results showed that the maximum quercetin was obtained with methanol as solvent followed by ethanol in both the pomegranate varieties. The results also indicated that peel powders of Bhagwa variety had significantly a higher recovery of quercetin as compared to Ganesh. The methanol and ethanol solvent are accounted for suitable solvents for the extraction of quercetin compound as compared to other solvents due to higher polarity and efficiency ${ }^{41}$. 
Punicalagin. The results pertaining to extraction and recovering of punicalagin compound from pomegranate peel powders are shown Figure 5. The punicalagin compound was estimated through HPLC and has been expressed as $\mathrm{mg} / \mathrm{g}$ of peel powder. The results indicated that there was a significant impact of specific solvent used to extract the punicalagin in both Bhagwa and Ganesh peel powders. Apart from solvents used, there was also a significant impact of the method of drying to prepare the peel powders on punicalagin. Among various solvents used, extracts prepared with methanol solvent showed the highest punicalagin in all the three types of peel powders (freeze dried, tray dried and sun dried) followed by ethanol, water, and acetone in both the pomegranate varieties.

The least amount of punicalagin was recovered with acetone and hexane being used as an extraction solvent. The punicalagin compound recovered using different solvents were also statistically significant with respect to each other for a specific type of drying treatment. In peel powder of Bhagwa, the statistically significant and maximum amount of punicalagin compound $(15.20 \pm 0.20 \mathrm{mg} / \mathrm{g})$ was recorded in freeze dried peel powder. This punicalagin compound was also statistically significant and highest as compared to all other solvents and drying treatments. The second best result was obtained with ethanol solvent in freeze dried powder $(13.80 \pm 0.02 \mathrm{mg} / \mathrm{g})$ followed by methanol solvent in tray dried powder $(11.20 \pm 0.02 \mathrm{mg} / \mathrm{g})$. Among various drying treatments, the statistically significant and highest punicalagin compound was recovered in freeze dried powder followed by tray dried and sun dried peel powders. The least punicalagin compound was recovered in sun dried peel powder. The punicalagin compound as observed in different drying treatments was also statistically significant with respect to each other for a specific type of solvent. The peel powder obtained from all respective drying (freeze drying, tray drying, and sun drying) methods were not recovered punicalagin compound with acetone and hexane solvent respectively. In peel powder of Ganesh, the statistically significant and maximum recovery of punicalagin compound $(7.30 \pm 0.01 \mathrm{mg} / \mathrm{g})$ was recorded in freeze dried peel powder. This punicalagin content was also statistically significant and highest as compared to all other solvents and drying treatments. The second best result was obtained with ethanol solvent in freeze dried powder $(4.60 \pm 0.02 \mathrm{mg} / \mathrm{g})$. The similar trend of results was also observed in peel powder obtained from tray drying method. It was also noted that the peel powder obtained from freeze drying and tray drying method was not recovered punicalagin compound with acetone and hexane solvent respectively. In sun dried peel powder extraction was also not recovered the punicalagin compound with water, acetone and hexane solvent due to lower efficiency to extract phenolic compounds from pomegranate peel. the results of present study are in line with previous study done by Singh et al., ${ }^{38}$; those reported higher recovery of punicalagin compound with methanol as solvent followed by ethanol in both the pomegranate varieties. The results also indicated that peel powders of Bhagwa variety had a higher recovery amount of punicalagin compound as compared to Ganesh. The results demonstrated that the freeze drying method and methanol solvent for extraction was significant potential to retaining and extraction the higher amounts of punicalagin content as compared to other drying methods and solvents.

In Summary, the Bhagwaextract exhibited the greatestquantity of phenolics such as gallic acid, punicalagin, quercetin and ellagic acid compared with Ganeshextract. Methanolic extract exhibited the 
greatestamount of phenolicssuch as ellagic acid, gallic acid and Punicalagin. The highest quantity of gallic acid was detectedforBhagwa in aqueous solvent. The study reported that hexane and acetone solvents are not suitable for the phenolic extractions in pomegranate peels. Overall the freezing drying method and methanol as extraction solvent for extraction bioactive compounds from pomegranate peel are highly recommended. Further studies are needed to explore to check the efficiency of combination of solvents (polar/non-polar) for higher recovery of natural bioactive compounds from pomegranate peel waste and other natural sources for further application in food and pharmaceutical sectors at commercial scale.

\section{Discussion}

The freeze drying method and methanol solvent are significantly accounted to recover a higher amount of ellagic acid from pomegranate peel as compared to respective drying treatments and solvents. The hexane solvent was not detected to quantify biological compounds from pomegranate peel powder due to lower efficiency to extract high polar compounds ${ }^{17,39}$. The results have showed that the maximum gallic acid was obtained with methanol as a solvent followed by ethanol in both the pomegranate varieties. The results also indicated that peel powders of Bhagwa variety recovered significantly higher amount of gallic acid as compared to Ganesh. The results demonstrated that the freeze drying method is significant potential to recovering the higher amounts of gallic acid as compared to other drying methods 33. Quercetin phenolic content was significantly higher obtained with methanol as solvent followed by ethanol in both the pomegranate varieties. The results also indicated that peel powders of Bhagwa variety had significantly a higher recovery of quercetin as compared to Ganesh. The methanol and ethanol solvent are accounted for suitable solvents for the extraction of quercetin compound as compared to other solvents due to higher polarity and efficiency ${ }^{41}$. In case of punicalagin compounds, the sun dried peel powder was not potential to extract punicalagin compounds with water, acetone and hexane solvent due to lower efficiency to extract phenolic compounds from pomegranate peel.

Overall results of the present investigation are supported by the previous findings reported by Mphahlele et al., 9; John et al., ${ }^{31}$; Ngo et al., ${ }^{32}$; Buitrago et al., 33 ; Qu et al., ${ }^{36}$; Farag et al., ${ }^{37}$; Singh et al., ${ }^{38}$ and Cheng et al., ${ }^{17}$. They reported the drying method had a direct impacts on the recovery of bioactive compounds from pomegranate peel. The freezing drying is most desirable method to retain the higher amount of bioactive compounds such as ellagic acid, gallic acid, quercetin and punicalagin of pomegranate peel. They also confirmed that the methanol as extract solvent is more potential to recover higher amount of gallic acid, ellagic acid, quercetin and punicalagin content from pomegranate peel powder due to high polar nature of methanol. The non-polar solvent such as hexane is not potential to recovering the bioactive contents from pomegranate peel powders.

\section{Declarations}

Acknowledgements 
The authors are grateful to the National Institute of Food Technology Entrepreneurship and Management, Kundli-131028 (Sonipat), Haryana, India for providing infrastructural and financial support for experimental workand Sophisticated Industrial Materials Analytic (SIMA) Lab Pvt. Ltd. Delhi Indiafor providing HPLC analysis facility. Taif University Researchers Supporting Project Number (TURSP2020/307), Taif University, Taif, Saudi Arabia for APC.

\section{Author contributions}

N.K., conceptualization, methodology, investigation, resources, formal analysis, writing-original draft, writing-review \& editing, and visualization; P., R.S., E.K., S.J.A.,A.A.M.,methodology, formal analysis, visualization, and writing-review and editing; N., supervision and writing-review and editing; R.S., E.K., S.J.A., A.A.M.; APC funding and writing-review and editing. All authors have read and agreed to the published version of the manuscript.All authors reviewed the manuscript.

\section{Competing interests}

The authors declare no competing interests

\section{Additional information}

Correspondence and requests for materials should be addressed to Neeraj and Rokayya Sami

\section{References}

1. Kumar, N., Pratibha, N. \& Sharma, S. Effect of solvents on physiochemical properties of freeze-dried pomegranate seed (Cv. Bhagwa). Int. J. Fruit Sci. 20, 590-604 https://doi.org/10.1080/15538362.2020.1747042 (2020).

2. Kumar, N., TrajkovskaPetkoska, A., Khojah, E., Sami, R. \& Al-Mushhin, A. A. Chitosan edible films enhanced with pomegranate peel extract: study on physical, biological, thermal, and barrier properties. Materials. 14, 3305 https://doi.org/10.3390/ma14123305 (2021).

3. Opara, U. L., Al-Ani, M. R. \& Al-Shuaibi, Y. S. Physico-chemical properties, vitamin C content and antimicrobial properties of pomegranate fruit (Punicagranatum L.). Food Bioprocess Technol, 2, 315-321 https://doi.org/10.1007/s11947-008-0095-5 (2009).

4. Zahin, M., Aqil, F. \& Ahmad, I. Broad spectrum antimutagenic activity of antioxidant active fraction of Punicagranatum L. peel extracts.Mutat. Res.703,99-107. DOI: 10.1016/j.mrgentox.2010.08.001 (2010)

5. Glazer, I. et al. Partial identification of antifungal compounds from punicagranatum peel extracts. $J$ Agric Food Chem, 60, 4841-4848 https://doi.org/DOI: 10.1021/jf300330y (2012).

6. Fawole, O. A., Opara, U. L. \& Chen, L. Bioaccessibility of total phenolic concentration and antioxidant capacity of pomegranate fruit juice and marc after in vitro digestion. Acta Hort, 1079, 285-290 https://doi.org/DOI: 10.17660/ActaHortic.2015.1079.34 (2015). 
7. Pirzadeh, M. et al. Pomegranate as a source of bioactive constituents: A review on their characterization, properties and applications. Crit. Rev. Food Sci. Nutr, 61, 982-999 https://doi.org/10.1080/10408398.2020.1749825 (2020).

8. Fawole, O. A., Makunga, N. P. \& \&Opara, U. L. Antibacterial, antioxidant and tyrosinase-inhibition activities of pomegranate fruit peel methanolic extract. BMC Complement Altern Med, 12, 200 https://doi.org/DOI: 10.1186/1472-6882-12-200 (2012).

9. Mphahlele, R. R. et al. Effect of drying on the bioactive compounds, antioxidant, antibacterial and antityrosinase activities of pomegranate peel. BMC Complement Altern Med, 16, 143 https://doi.org/10.1186/s12906-016-1132-y (2016).

10. Kumar, N. \& \&Neeraj, D. Study on physico-chemical and antioxidant properties of pomegranate peel. J. Pharmacogn. Phytochem, 7, 2141-2147 https://doi.org/DOI: 10.22271/phyto (2018).

11. Gözlekçi, Å., Saraçoğlu, O., Onursal, E. \& \&Özgen, M. Total phenolic distribution of juice, peel, and seed extracts of four pomegranate cultivars. Pharmacogn. Mag, 7, 161-164 https://doi.org/DOI: 10.4103/0973-1296.80681 (2011).

12. Sood, A. \& Gupta, M. Extraction process optimization for bioactive compounds in pomegranate peel. Food Biosci. 12, 100-106 https://doi.org/DOI: 10.1016/j.fbio.2015.09.004 (2015).

13. Krokida, M. K., Karathanos, V. T., Maroulis, Z. B. \& Marinos-Kouris, D. Drying kinetics of some vegetables. J Food Eng, 59, 391-393 https://doi.org/10.1016/S0260-8774(02)00498-3 (2003).

14. Sablani, S. S. Drying of fruits and vegetables: retention of nutritional/functional quality. Drying Technol, 24, 123-135 https://doi.org/10.1080/07373930600558904 (2006).

15. Tang, W., Zhang, M., Adhikari, B. \& \&Mujumdar, A. S. Effects of preparation and drying methods on the antioxidant activity of enzymatically hydrolyzed porcine placenta hydrolysates. DryingTechnol, 31, 13-4 https://doi.org/10.1080/07373937.2013.808660 (2013).

16. Chiewchan, N., Mujumdar, A. S. \& \&Devahastin, S. Application of drying technology to control aflatoxins in foods and feeds: a review. Drying Technol, 33, 1700-1707 https://doi.org/10.1080/07373937.2015.1068795 (2015).

17. Cheng, K. et al. Evaluation of the impact of different drying methods on the phenolic compounds, antioxidant activity, and in vitro digestion of green coffee beans. Food Sci. Nutr, 7, 1084-1095 https://doi.org/doi: 10.1002/fsn3.948 (2019).

18. Maskan, M. Microwave/air and microwave finish drying of banana. J Food Eng, 44, 71-78 https://doi.org/10.1016/S0260-8774(99)00167-3 (2000).

19. Attanasio, G., Cianquanta, L. \& Matteo, M. D. Effect of drying temperature on physic-chemical properties of dried and rehydrated chestnuts (Castanea Sativa). Food Chem, 88, 583-590 https://doi.org/DOI: 10.1016/j.foodchem.2004.01.071 (2004).

20. Di Scala, K. \& \&Crapiste, G. Drying kinetics and quality changes during drying of red pepper.LWT Food Sci Technol.41,789-795.https://doi.org/10.1016/j.Iwt.2007.06.007(2008)

21. Vega-Gàlvez, A. et al. Effect of air-drying temperature on physico-chemical properties, antioxidant capacity, colour and total phenolic content of red pepper (Capsicum annuum, L. var. 
Hungarian).Food Chem.117,647-653.https://doi.org/10.1016/j.foodchem.2009.04.066(2009)

22. Ratti, C. Hot air and freeze-drying of high-value foods: a review. J Food Eng, 49, 311-319 https://doi.org/10.1016/S0260-8774(00)00228-4 (2001).

23. Soysal, A., Oztekin, S. \& \&Eren, O. Microwave drying of parsley: modelling, kinetics, and energy aspects. Biosyst Eng.93,403-413.https://doi.org/10.1016/j.biosystemseng.2006.01.017(2006)

24. Therdthai, N. \& Zhou, W. Characterization of microwave vacuum drying and hot air drying of mint leaves (MenthacordifoliaOpizexFresen). J Food Eng, 91, 482-489 https://doi.org/DOI: 10.1016/j.jfoodeng.2008.09.031 (2009).

25. Korus, A. Effect of preliminary processing, method of drying and storage temperature on the level of antioxidants in kale (Brassica oleracea L. var. acephala) leaves. LWT Food Sci Technol, 44, 17111716 https://doi.org/10.1016/j.Iwt.2011.03.014 (2011).

26. Hayouni, E. A., Abedrabba, M., Bouix, M. \& \&Hamdi, M. The effects of solvents and extraction method on the phenolic contents and biological activities in vitro of Tunisian Quercuscoccifera L. and Juniperusphoenicea L. fruit extracts. Food Chem.105,11261134.https://doi.org/10.1016/j.foodchem.2007.02.010(2007)

27. González-Montelongo, R., Lobo, M. G. \& González, M. Antioxidant activity in banana peel extracts: Testing extraction conditions and related bioactive compounds.Food Chem.119,10301039.https://doi.org/10.1016/j.foodchem.2009.08.012(2010)

28. Ghafoor, K., Park, J. \& Choi, Y. H. Optimization of supercritical fluid extraction of bioactive compounds from grape (Vitislabrusca B.) peel by using response surface methodology. Innov Food SciEmerg Technol.11,485-490.https://doi.org/10.1016/j.ifset.2010.01.013(2010)

29. Sasidharan, S. et al. Extraction, isolation and characterization of bioactive compounds from plants' extracts. Afr J Tradit Complement Altern Med, 8, 1-10. PMC3218439 ((2011).

30. Rajan, M., Rajkumar, G., Guedes, T. J. F. L. \& Barros, R. G. C.\&Narain, N. Performance of different solvents on extraction of bioactive compounds, antioxidant and cytotoxic activities in Phoenix loureiroiKunth leaves.J Appl Res Med Aromat

Plants.17,100247.https://doi.org/10.1016/j.jarmap.2020.100247(2020)

31. John, M. K. M., Bhagawat, A. A. \& \&Luthgria, D. L. Swarm motility inhibitory and antioxidant activities of pomegranate peel processed under three drying conditions. Food Chem.235,145153.https://doi.org/10.1016/j.foodchem.2017.04.143(2017)

32. Ngo, T. V., Scarlett, C. J., Bowyer, M. C., Ngo, P. D. \& \&Vuong, Q. V. Impact of different extraction solvents on bioactive compounds and antioxidant capacity from the root of Salaciachinensis $L$. J. Food Qual, 9305047, 1-8 https://doi.org/.10.1155/2017/9305047( (2017).

33. Buitrago, D., Buitrago-Villanueva, I., Barbosa-Cornelio, R. \& Coy-Barrera, E. Comparative Examination of Antioxidant Capacity and Fingerprinting of Unfractionated Extracts from Different Plant Parts of Quinoa (Chenopodium quinoa) Grown under Greenhouse Conditions. Antioxidants, 8, 238 https://doi.org/10.3390/antiox8080238( (2019). 
34. Elango, S., Balwas, R. \& Vijaya Padma, V. V. Gallic Acid Isolated from Pomegranate Peel Extract Induces Reactive Oxygen Species Mediated Apoptosis in A549 Cell Line. J. Cancer Ther, 2, 638-645 https://doi.org/DOI: 10.4236/jct.2011.25085 (2011).

35. Venkataramanamma, D., Aruna, P. \& \&Singh, R. P. Standardization of the conditions for extraction of polyphenols from pomegranate peel. J. Food Sci. Technol, 53, 2497-2503 https://doi.org/DOl: 10.1007/s13197-016-2222-z (2016).

36. Qu, W., Breksa, I. I. I., Pan, A. P. \& Ma, H. Z. \& Quantitative determination of major polyphenol constituents in pomegranate products.Food Chem.132,5851591.https://doi.org/10.1016/j.foodchem.2011.11.106(2012)

37. Farag, R. S., Abdel-Latif, M. S., Emam, S. S. \& \&Tawfeek, L. S. Phytochemical screening and polyphenol constituents of pomegranate peels and leave juices. Agriculture and Soil Sciences, 1, 8693 (2014). http://www.landmarkresearchjournals.org/lrjass/index.php(

38. Singh, M. et al. Influence of the solvents on the extraction of major phenolic compounds (punicalagin, ellagic acid and gallic acid) and their antioxidant activities in pomegranate aril. J. Food Sci. Technol, 51, 2070-2077 https://doi.org/DOI: 10.1007/s13197-014-1267-0 (2014).

39. Negi, P. S., Jayaprakasha, G. K. \& Jena, B. S. Antioxidant and antimutagenic activities of pomegranate peel extracts. Food Chem, 80, 393-397 https://doi.org/10.1016/S03088146(02)00279-0 (2003).

40. Balasnram, N., Sundram, K. \& \&Samman, S. Phenolic compounds in plant and agri-industrial byproducts: antioxidant activity, occurrence and potential uses. Food Chem, 99,191203.https://doi.org/10.1016/j.foodchem.2005.07.042(2006)

41. Middha, S. K., Usha, T. \& \&Pande, V. HPLC evaluation of phenolic profile, nutritive content, and antioxidant capacity of extracts obtained from Punicagranatum fruit peel. AdvPharmacol Sci, 296236, 1-6 https://doi.org/.10.1155/2013/296236 (2013).

42. Sangeetha, J. \& \&Vijayalakshmi, K. Physicochemical evaluation and chromatographic fingerprint profile of the rind of ganesh variety of Punicagranatum Linn. Int J Pharm Bio Sci, 3, 329-337 (2012).

43. Sawant, N. R. \& \&Chavan, A. R. Determination of Gallic acid from their Methanolic Extract of Punicagranatum By HPLC Method. Int.J.ChemTech Res, 5, 2598-2602 (2013).

\section{Figures}




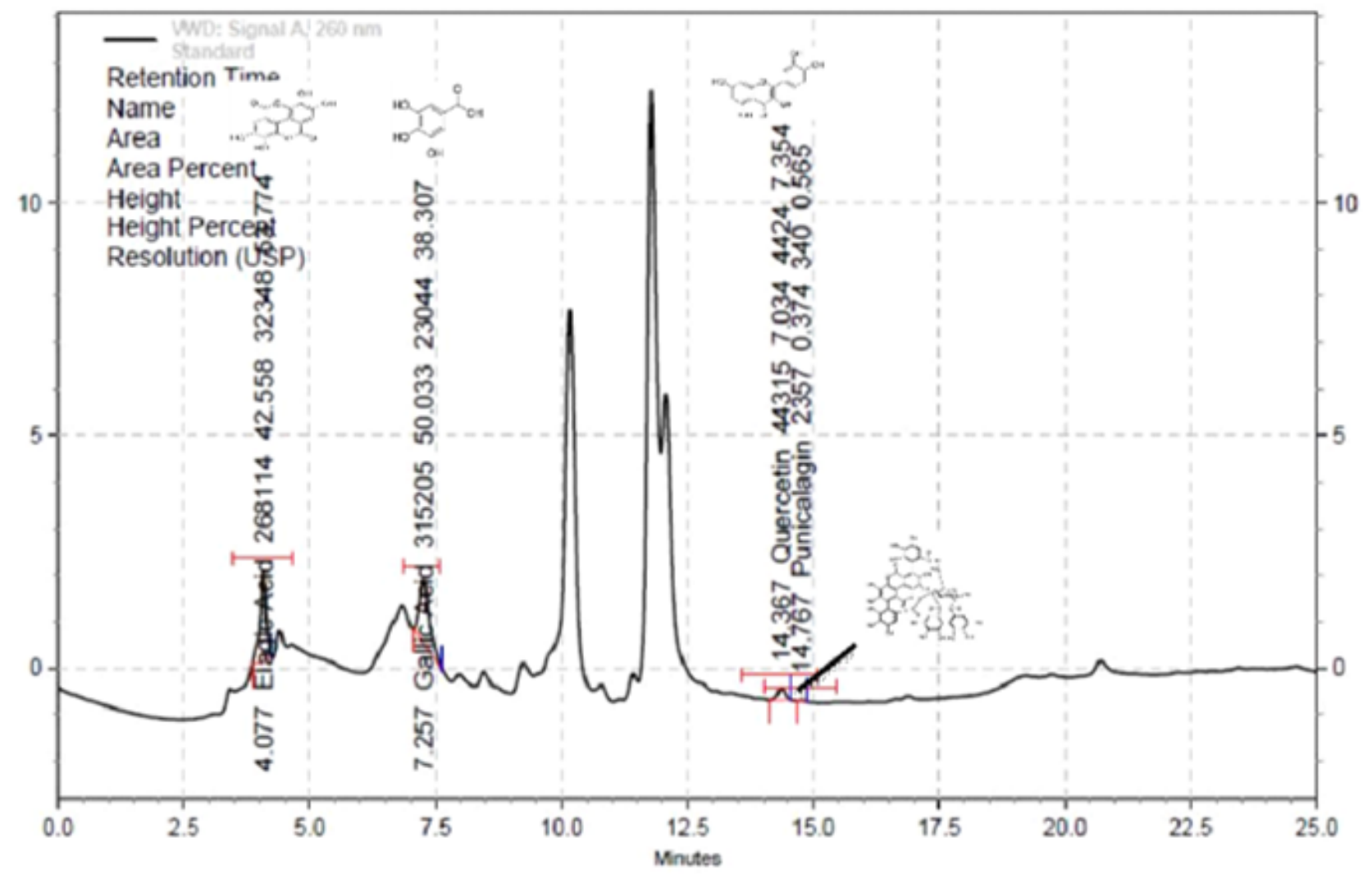

Figure 1

HPLC standards chromatogram of Ellagic acid, Gallic acid, Quercetin, and Punicalagin compounds
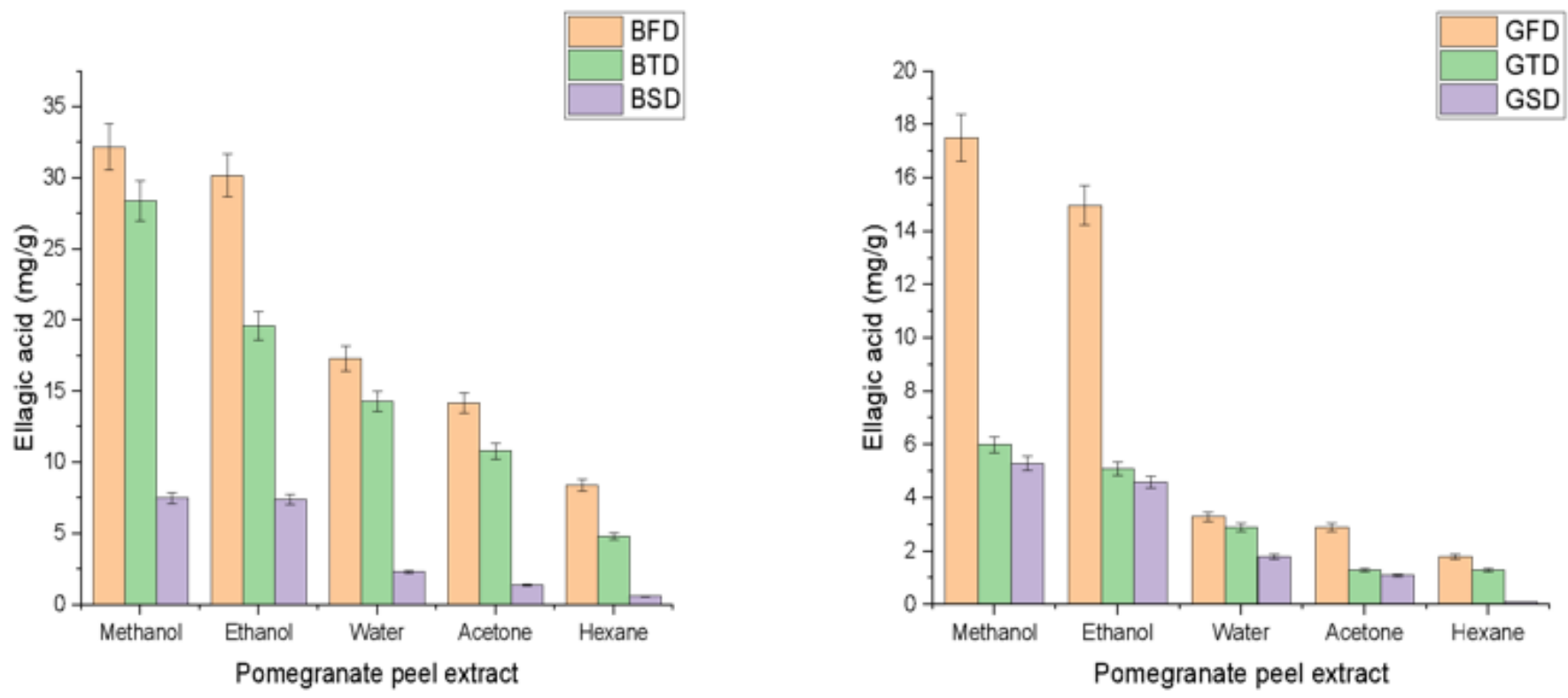

Bhagwa

Ganesh

Figure 2 
Ellagic acid $(\mathrm{mg} / \mathrm{g})$ of pomegranate peel extracts $(\mathrm{BFD}=$ Bhagwa freeze dried, $\mathrm{BTD}=$ Bhagwa tray dried, $\mathrm{BSD}=$ Bhagwa sun dried, $\mathrm{GFD}=\mathrm{Ganesh}$ freeze dried, $\mathrm{GTD}=$ Ganesh tray dried, $\mathrm{GSD}=$ Ganesh sun dried, N= 3)

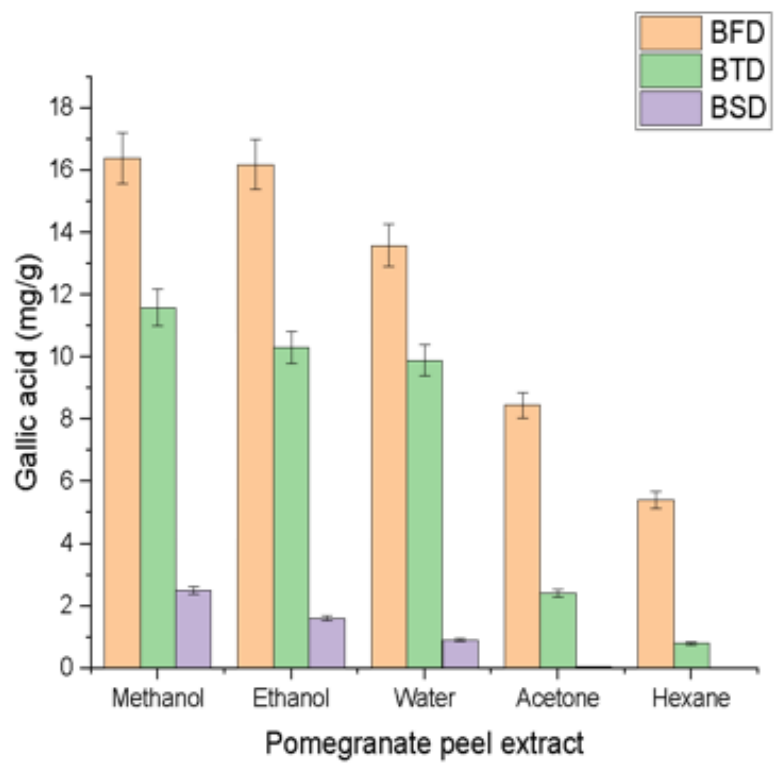

Bhagwa

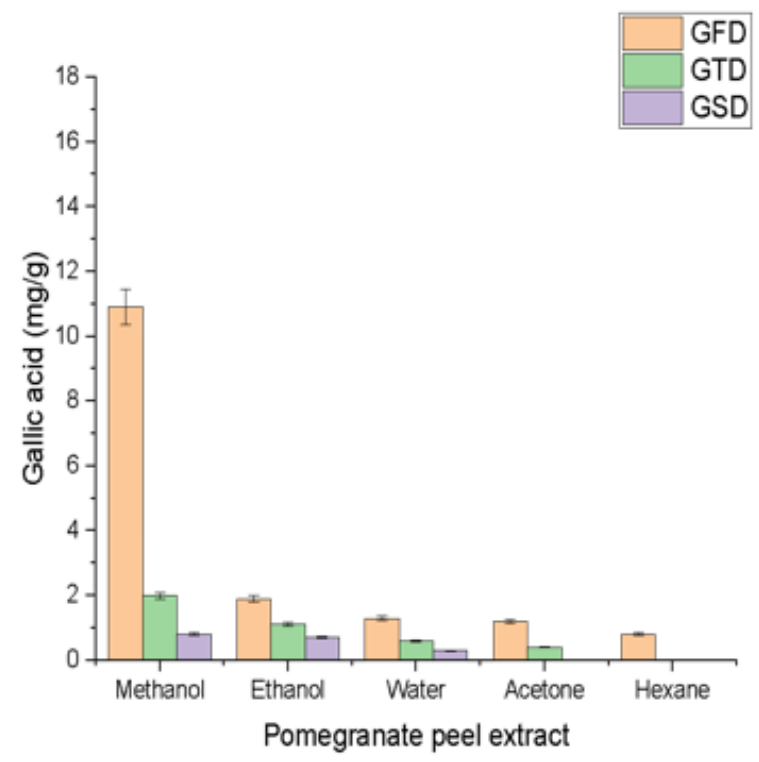

Ganesh

\section{Figure 3}

Gallic acid $(\mathrm{mg} / \mathrm{g})$ of pomegranate peel (BFD = Bhagwa freeze dried, BTD= Bhagwa tray dried, $\mathrm{BSD}=$ Bhagwa sun-dried, GFD=Ganesh freeze dried, GTD= Ganesh tray dried, GSD= Ganesh sun-dried, N= 3)

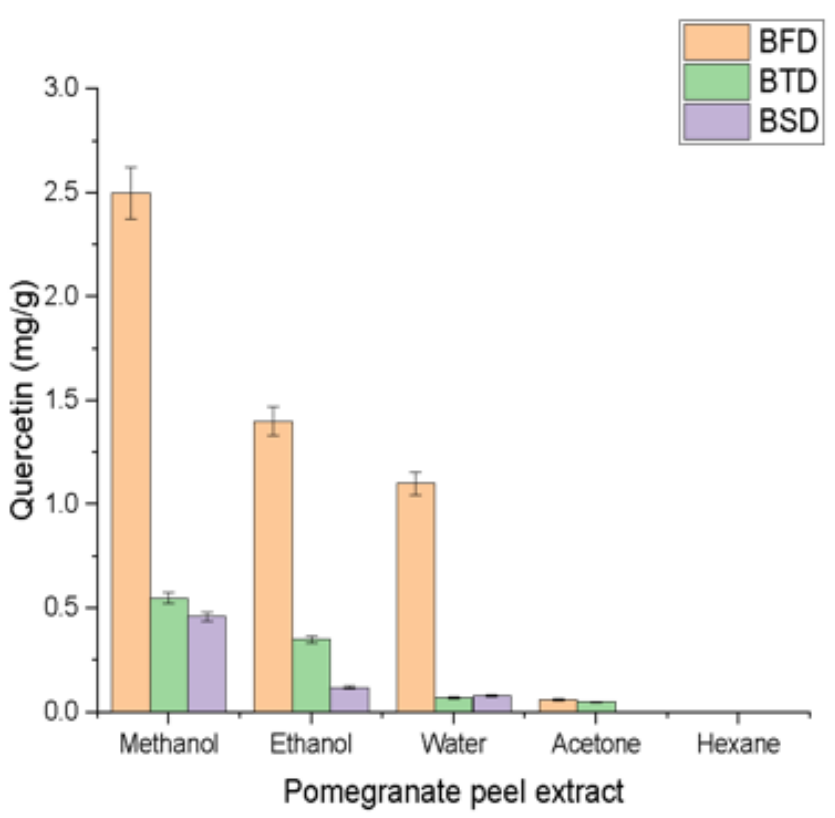

Bhagwa

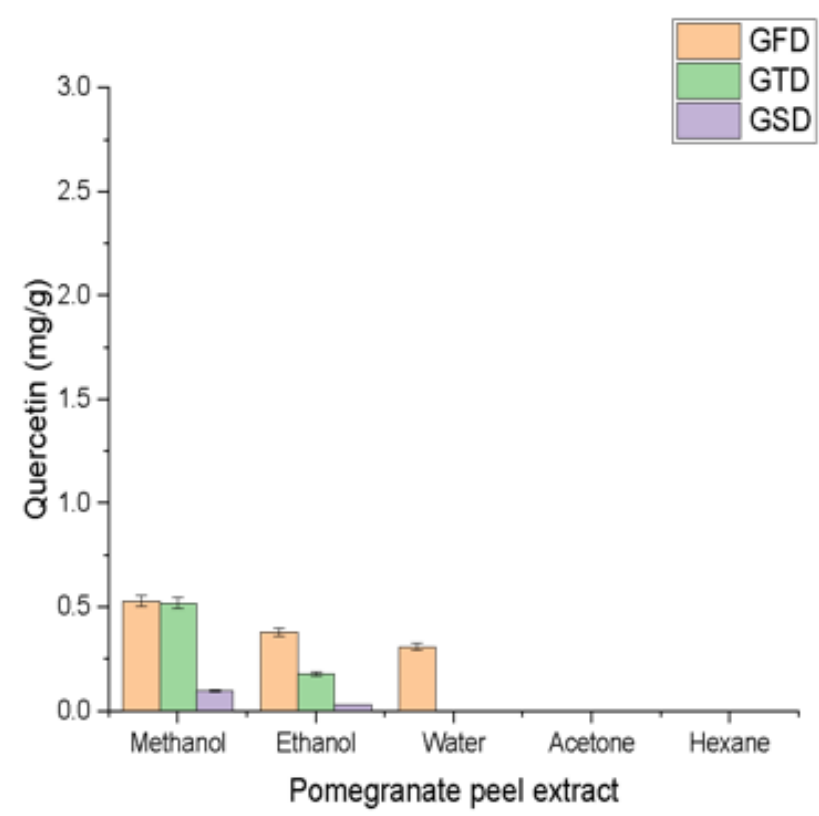

Ganesh 
Figure 4

Quercetin $(\mathrm{mg} / \mathrm{g})$ of pomegranate peel $(\mathrm{BFD}=$ Bhagwa freeze dried, BTD= Bhagwa tray dried, BSD= Bhagwa sun-dried, GFD=Ganesh freeze dried, GTD= Ganesh tray dried, GSD = Ganesh sun-dried, N=3)

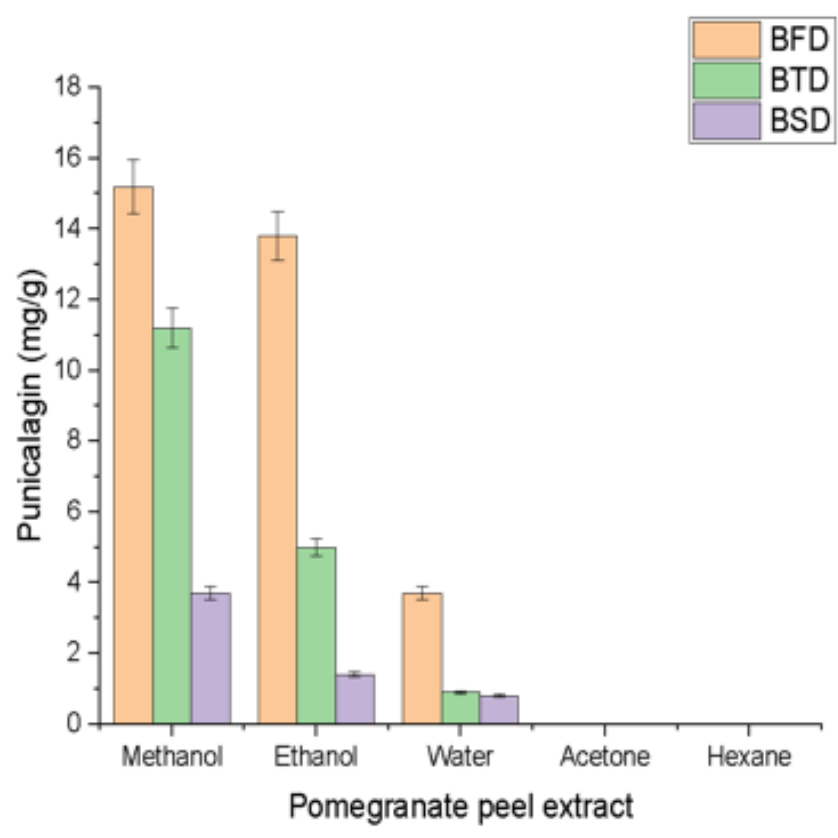

Bhagwa

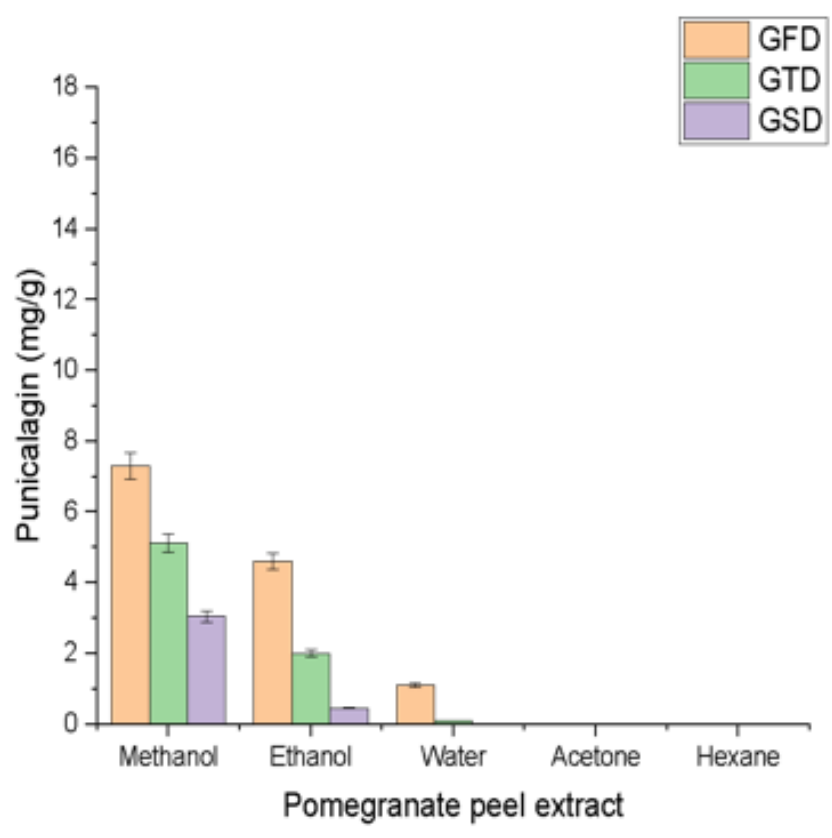

Ganesh

\section{Figure 5}

Punicalagin $(\mathrm{mg} / \mathrm{g})$ of pomegranate peel $(\mathrm{BFD}=$ Bhagwa freeze dried, $\mathrm{BTD}=$ Bhagwa tray dried, $\mathrm{BSD}=$ Bhagwa sun-dried, GFD=Ganesh freeze dried, $T D=$ Ganesh tray dried, GSD = Ganesh sun-dried, N=3) 


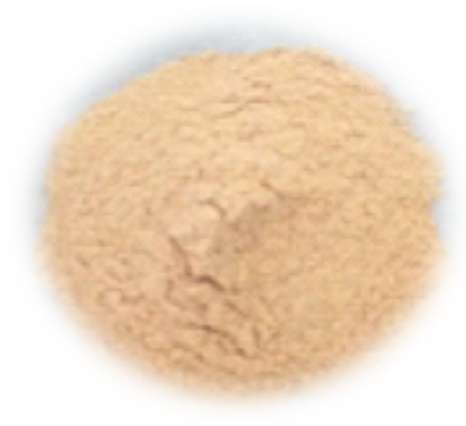

BFD

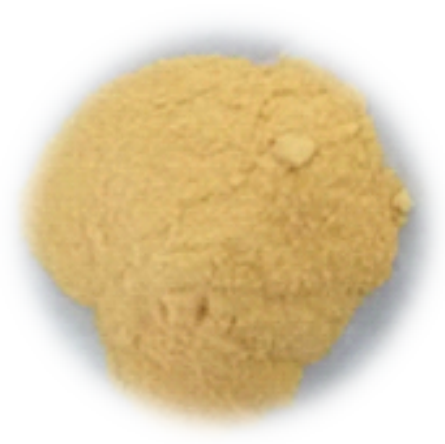

GFD

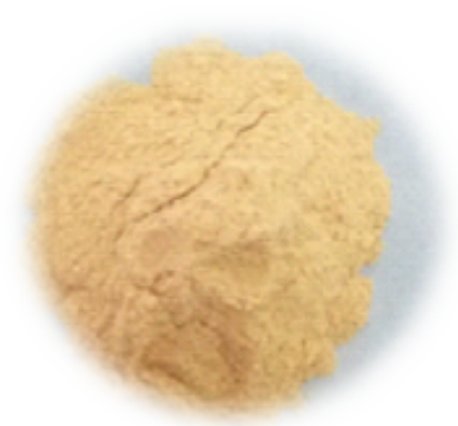

BTD

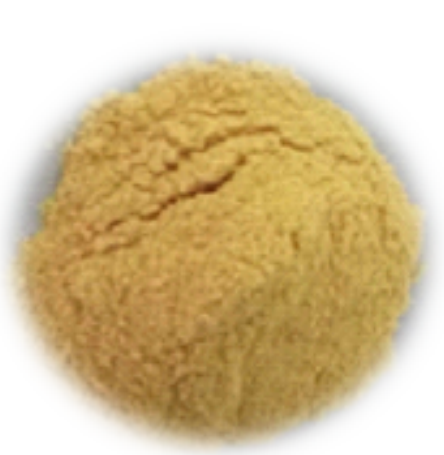

GTD

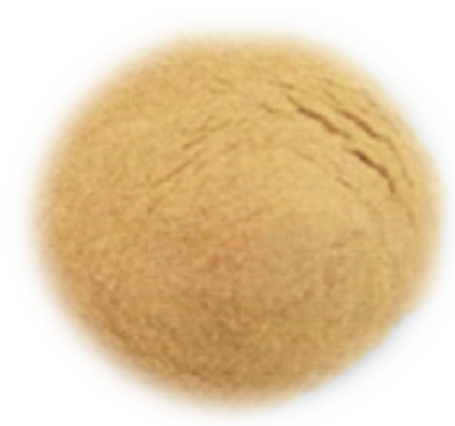

BSD

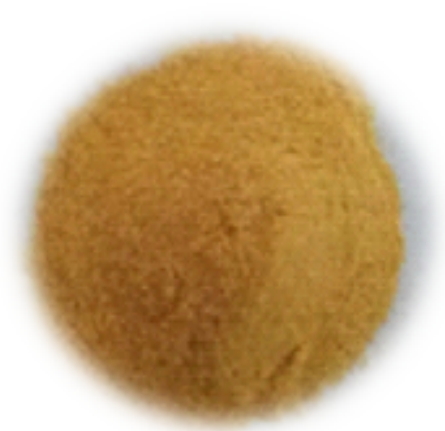

GSD

\section{Figure 6}

Different dried pomegranate peel powders Where; BFD= Bhagwa freeze dried, BTD= Bhagwa tray dried, $\mathrm{BSD}=$ Bhagwa sun dried, GFD $=$ Ganesh freeze dried, $\mathrm{GTD}=$ Ganesh tray dried, $\mathrm{GSD}=$ Ganesh sun dried 